\title{
UC-NRLF
}

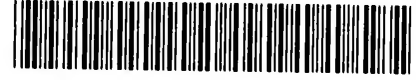

В 4539 660

QC

721

F9 
$\left(\begin{array}{ccc}3 & \end{array}\right.$

a

$\therefore \quad \therefore \quad \because \because$

a

$\therefore \quad \therefore \quad \therefore \quad \therefore \quad \therefore$

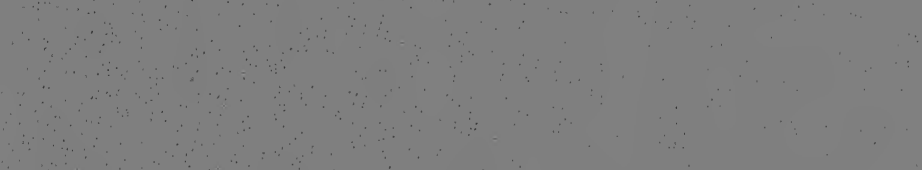
$\therefore \because \therefore \quad \therefore \quad \therefore \quad \therefore$

$\therefore \because \therefore \quad \therefore \quad \therefore \quad \therefore \quad \therefore$

$\left(\begin{array}{lll}3 \\ 2\end{array}\right.$

$\because \therefore \therefore \because \therefore \quad \therefore$

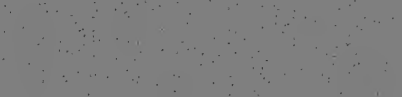

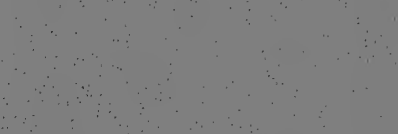

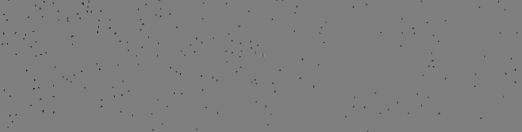

$\therefore \quad \therefore$

$\therefore \therefore$

$\therefore \quad \therefore \quad \therefore$

$\because \quad \because \quad \because \cdots \quad \ddots \quad \cdots$

$\because \cdots$

..

$\therefore \therefore$

$\because$

$\cdots$

$\therefore$

$\ldots+x^{2}=x^{2}$

$\therefore \quad \therefore$
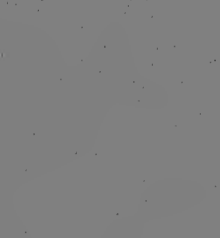

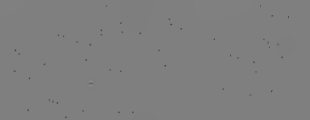




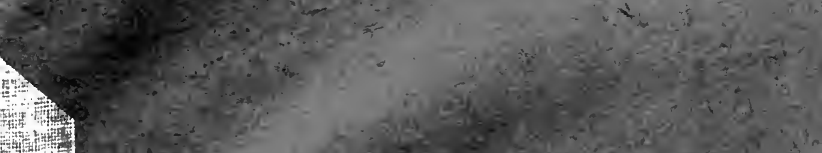




\section{THE ACTINIUM-URANIUM RATIO IN COLORADO CARNOTITE}

BY

KARL H. FUSSLER

A THESIS

Presented to the Faculty of the Graduate School of the University of Pennsylvania in Partial fulfilment of the Requirements for the Degree of Doctor of PhILOSOPHY 



\section{THE ACTINIUM-URANIUM RATIO IN COLORADO CARNOTITE}

BY

KARL H. FUSSLER

III

\section{A THESIS}

Presented to the Faculty of the Graduate School of the University of Pennsylvania in Partial Fulfilment of the Requirements for the Degree of Doctor of Philosophy 
Digitized by the Internet Archive in 2007 with funding from Microsoft Corporation 


\section{$Q C$ \\ 721 \\ Fq}

THE ACTINIUM-URANIUM RATIO IN COLORADO CARNOTITE. 


\section{THE ACTINIUM-URANIUM RATIO IN COLORADO CARNOTITE.}

By Karl H. Fussler.

$\mathrm{T}^{\mathrm{T}}$ is generally accepted by investigators in radio-activity that actinium

is a branch product from the uranium transformation series. This is based on the following facts: (I) Actinium is always found in uranium minerals; (2) Boltwood ${ }^{1}$ separated the actinium from North Carolina uraninite and determined the ratio of its activity, with its products in radio-active equilibrium, to the activity of the uranium with which it was associated. The values of this ratio, from the four determinations which he made, were $0.14,0.15,0.24$ and 0.36 . He gives the value 0.28 as the weighted mean of these results. (3) $\mathrm{He}^{1}$ also measured the total activity of various uranium minerals and determined what fraction of this total activity is due to each of the separate radio-elements contained in the minerals. His results indicate that the activity of a uranium mineral, containing equilibrium amounts of the various radio-elements, is about 4.7 times the activity of the uranium in the mineral. The sum of the activities of the separate radio-elements, uranium to polonium, plus $0.28 \times$ uranium for the actinium series, gives $4.64 \times$ uranium as the total activity of the mineral. If actinium is a branch product of the uranium series there should be a constant ratio between the activities of the actinium and of the uranium in all uranium minerals.

Since this ratio has been directly measured for only one uranium mineral and for only two specimens of that mineral ${ }^{2}$ it was thought desirable to determine it using another uranium mineral. This paper describes the experiments carried out using Colorado carnotite.

Through the courtesy of the Cummings Chemical Company, manufacturers of radium, of Lansdowne, Pa., I was enabled to select my specimens from ton lots of mineral. Only large, firm lumps of the higher grade ores were chosen. The final selection was made at the laboratory from the bulk of the mineral brought from the factory, and, as a rule, only the centers of the larger lumps were chosen. The two

${ }^{1}$ Boltwood, Amer. Jour. Sci., XXV., p. 269, 1908.

${ }_{2}^{2}$ The specimens used are described by Boltwood as no. 3 and no. 4 uraninite from Spruce Pine, N. C. Two of the results were obtained from one sample of specimen no. 3, one result from another sample of the same specimen, and one from a sample of specimen no. 4 . 
specimens finally selected represented two different shipments of ore. Specimen A after pulverizing and passing through a 40-mesh screen consisted of about 300 grams of carnotite. Specimen B was a lower grade material. There were about 75 grams in this lot.

The radio-active measurements were made in an alpha-ray electroscope which will not be described as it differed in no essential detail from one described by Boltwood. ${ }^{1}$ The gold-leaf was charged by connecting, through a water resistance, to the negative terminal of a 400-volt battery of "Spindler and Hoyer" cadmium cells. The guard ring was permanently connected to the negative terminal of the battery. The case of the electroscope and the positive terminal of the battery were connected to earth.

A microscope, with a graduated scale in the eye-piece, was rigidly clamped in front of the electroscope. The readings consisted in timing the passage of the tip of the gold-leaf over a certain definite portion of the graduated scale. The sensitiveness of the electroscope was determined for every series of measurements by taking a reading of the leak produced by a standard film of uranium oxide. This standard was made several years ago by Professor D. H. Kabakjian, from a very pure specimen of uranium oxide. It was deposited in the form of a thin film on a light brass disc. It has been carefully preserved and from time to time its activity has been compared with the activity of a primary uranium standard, which was similarly prepared, and which has been used only as a comparison specimen for the secondary standards.

The natural leak of the electroscope was determined for every series of measurements and the corrections made for it. It was fairly low and has not varied materially during the past one and one half years.

The general plan of the experiments was to separate chemically the ionium, radio-actinium, and actinium, as a group, with the rare earths as oxalates, from the other radio-elements in a specimen of carnotite, to determine the weight of the mixture of these elements and the nonradio-active elements separated with them and to make a very thin film, of known weight, on a metal plate, from this active material. The growth of activity of this film was measured at intervals over a period of about Ioo days, at which time the equilibrium value had been attained. The activity due to ionium and actinium plus its products in equilibrium in one gram of carnotite was calculated from the equilibrium value of the activity of this film. A film, of known weight, was also made from the uranium separated from the same specimen of mineral. The activity due to the uranium alone in one gram of carnotite was calculated from

1 loc. cit., p. 272. 
the activity of this film. Boltwood ${ }^{1}$ has shown that the activity of ionium in a uranium mineral is 34 per cent. of the activity of the uranium with which it is associated. This result was used in calculating the activity of the ionium per gram of mineral. Deducting the activity due to ionium, from the combined activity of ionium and the actinium series, gives the value of the activity due to actinium and its products in equilibrium in one gram of the mineral. This latter value divided by the activity due to the uranium in one gram of the mineral gives the value of the actinium-uranium activity ratio.

Because of the minute quantities of these radio-elements in a mineral the usual method used in separating them is to introduce into the solutions other elements, or carriers, which are either isotopic, or chemically similar to them. The best method of separating ionium from a mineral is to introduce thorium, if not already present, and then separate the thorium by the well-known chemical processes. Wishing to avoid the introduction of another radio-element, cerium was used as a carrier, the chemical properties of which are not very different from those of ionium. In the same way lanthanum was used as a carrier for the actinium. ${ }^{2}$ As radio-actinium is isotopic with ionium, ${ }^{3}$ evidently it will be precipitated with the ionium. The details of the experiments are as follows:

Experiment I.-Twenty-five grams of specimen A carnotite were decomposed by heating with dilute nitric acid and the solution evaporated to dryness. The residue was treated with hot dilute nitric'acid. The insoluble matter was separated by decantation and again treated with the hot dilute acid. The solutions were combined and the insoluble matter, consisting largely of silica, after washing, was found to have negligible activity. The solution was saturated with hydrogen sulphide to separate the insoluble sulphides after the addition of a small quantity of bismuth nitrate to ensure complete precipitation of the polonium. The filtrate was boiled to remove the excess of hydrogen sulphide. Small amounts of cerium nitrate, and lanthanum nitrate, were added, and while the solution was still hot, an excess of oxalic acid was added and allowed to stand for about twenty hours. The precipitated oxalates were removed, a minute quantity of the cerium and lanthanum salts was again added, and the precipitation by oxalic acid repeated. ${ }^{4}$ The oxalates were combined, converted into nitrates, and again precipitated

${ }^{1}$ Loc. cit., p. 289.

2 Auer von Welsbach, Sitzungber. K. Akad. Wiss. Wien, I9ı, II9, ii., a, I.

${ }^{3}$ Fleck, Journ. Chem. Soc., I03', 381, r9r3.

4 In work preliminary to these experiments it was found that a third oxalate precipitate had a negligible activity. 
by oxalic acid. The oxalates were converted into oxides by intense ignition over the blast-lamp. The rare earth oxides obtained in this manner weighed 1.0230 grams. A film weighing 0.0082 gram was made. The activity of this film when it had reached equilibrium, was 5.202 divisions per minute. This gives $\frac{1.0230}{25 \times 0.0082} \times 5.202=26$ divisions per minute for the activity due to the ionium and the actinium, plus its products in equilibrium, in one gram of carnotite.

The filtrates, from which the oxalates were separated, were evaporated to dryness and gently heated to destroy the oxalic acid. The residue was taken up in dilute hydrochloric acid, a small amount of barium chloride was added, and the radium precipitated as sulphate with the barium. The addition and precipitation of the barium was twice repeated to ensure complete removal of the radium. The filtrate was boiled with an excess of sodium carbonate, containing some ammonium sulphide, and the carbonates filtered off. The uranium was precipitated and weighed as sodium uranate. It weighed 6.6042 grams and the film made from it weighed 0.0096 gram. The activity of the film was 1.990 divisions per minute. This gives an activity of 55 divisions per minute for the uranium in one gram of the mineral.

The activity of the ionium per one gram of the mineral, using Boltwood's value, should be $(0.34 \times 55)$ r 8.6 divisions per minute. Deducting this value from the activity calculated from the ionium-actinium film (26 divisions per minute per one gram of mineral) gives 7.4 divisions per minute as the activity due to actinium and its products in equilibrium. This is 0.135 times the activity of the uranium.

Experiment 2.-Fifty grams of specimen B carnotite were taken for this experiment. The material was treated in the same manner as that of experiment I. The activity of the ionium-actinium film 100 days after separation was 2.1 I6 divisions per minute which gave I 8.2 divisions per minute as the total activity of the ionium and actinium per one gram of mineral. The sodium uranate separated weighed 8.5234 grams, and the film weighed $0.004 \mathrm{I}$ gram, which showed an activity of 0.849 division per minute. This gave an activity of 35.2 divisions per minute for the uranium in one gram of carnotite. The activity of the ionium, calculated as before, is $(0.34 \times 35.3)$ r2.0 divisions per minute. Subtracting this from the combined ionium-actinium activity gives 6.2 divisions per minute as the activity of the actinium series. This divided by the activity of the uranium ( 35.3 divisions per minute) gives 0.176 as the value found for the ratio of the activity of the actinium and its products to that of the uranium with which it is associated. 
Experiment 3.-Twenty-five grams of specimen A carnotite were treated in the same manner as in experiment $\mathbf{I}$. The activity of the uranium per gram of carnotite was 5I.5 divisions per minute. The combined activity of the ionium and the actinium series per gram of carnotite was 23 divisions per minute. The calculated activity due to the ionium $(0.34 \times 5 \mathrm{I} .5)$ is 17.5 divisions per minute which leaves 5.5 divisions per minute as the activity due to actinium and its products in equilibrium. This divided by the activity of the uranium gives 0.107 as the actiniumuranium ratio.

The values for the relative activity of the actinium series obtained in these experiments were, therefore, 0.135, 0.176, and $0.107 \times U$ r.

A theoretical curve was plotted on the assumption that an equilibrium amount of radio-actinium was precipitated with the actinium. This curve was obtained by adding the ordinates of curves $I$ and II, Fig. I.

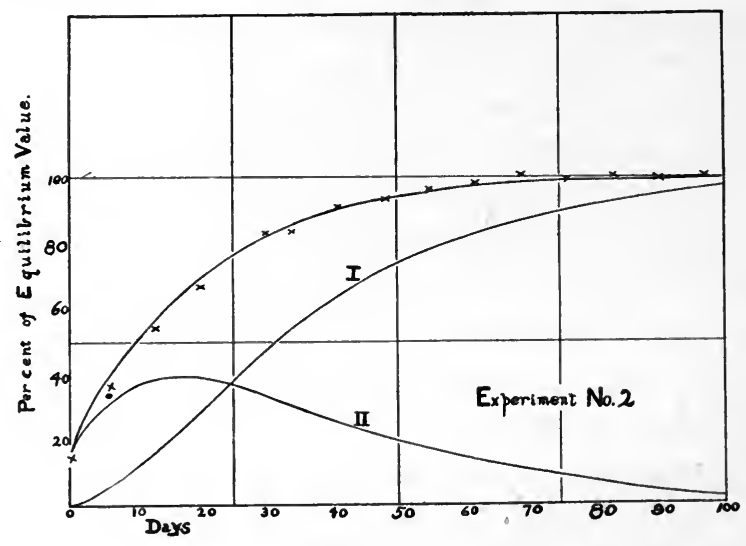

Fig. 1.

Curve $I$ is the recovery curve of actinium freed from all its active products. ${ }^{1}$ The ordinates represent the activity and the abscissae the time in days from separation. The equilibrium value of the activity is taken as roo. McCoy and Leman ${ }^{2}$ have shown that the equilibrium activity of radio-actinium is $\mathbf{I} 7.6$ per cent. of the total activity of the actinium series. This value is used as the initial value of the radio-actinium curve (Curve $I I$ ). The crosses give the experimental values of the growth with time of the activity of the film of experiment no. 2. The curves for experiments no. I and no. 3 were similar in shape, but with initial activities somewhat lower. ( 13.9 per cent. for no. I and II.7 per cent. for no. 3.) The agreement is well within the limits of experimental error. This, I believe, indicates that the film did not contain

${ }^{1}$ Hahn, Phil. Mag., XIII., I65, 1907.

2 Phys. Rev., 4 Ser. 2, I9I4, p. 409. 
other radio-active elements in quantities sufficient to appreciably alter the shape of the actinium plus radio-actinium curve. The disagreement between the experimental and the theoretical curves may be accounted for by an incomplete precipitation of the ionium in the specimens. A computation shows that if $\mathbf{I} .5$ per cent. (for film of experiment no. 2) of the ionium remained in the solution the starting point of the two curves would agree. This would make the actinium ratio larger by about 2.8 per cent.

\section{Conclusions.}

I. The ratio of the activity of the actinium series to the activity of the uranium associated with it in Colorado carnotite has been determined.

2. The results indicate that the quantity of actinium in carnotite is proportional to the quantity of uranium.

3. The value of the ratio is of the same order of magnitude, but somewhat lower than that obtained by Boltwood using North Carolina uraninite.

4. The results are in agreement with the theory that actinium is a branch product of the uranium series.

In conclusion I wish to acknowledge my indebtedness to Professor Arthur W. Goodspeed for kindly placing at my disposal all the facilities of the Randal Morgan Laboratory, and to Professor D. H. Kabakjian for suggesting the subject of this research and for his continued cooperation and valuable criticisms during the course of the investigation.

Randal Morgan Laboratory of Physics,

University of Pennsylvania. 



\section{.}



8 a 3 3

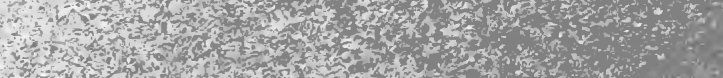

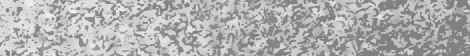
aty

r.t.

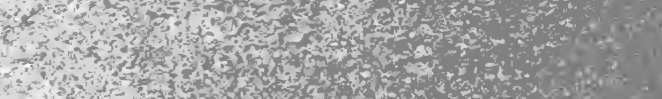

H.t.

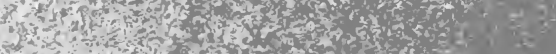

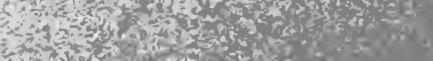

H.

(1)

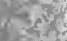

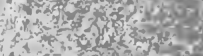

andis

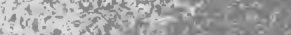

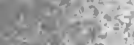

(1)

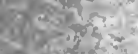

323 3.

atos

asto

$+x+5 \times 3$ a

If

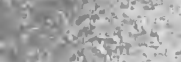

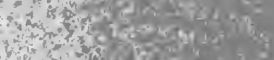

wing

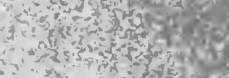

- an why

60 bर 20

as 300

axing

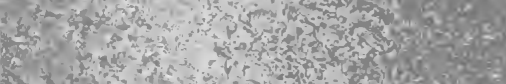

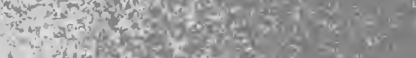

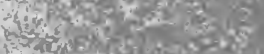

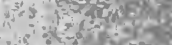

in

yand

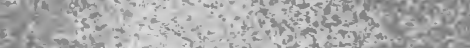

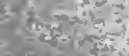

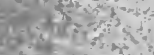

minges

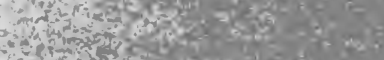

$2030, \frac{3}{2}$

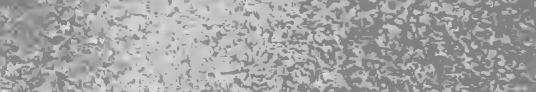

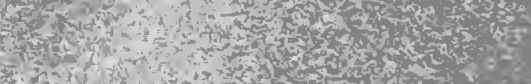

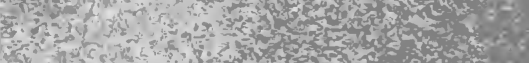

7 .

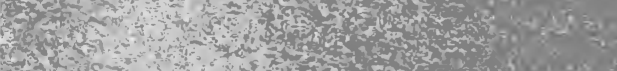

Bint.

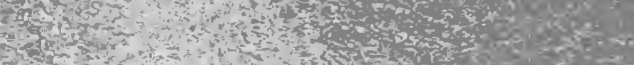

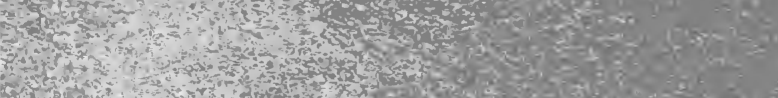

Q

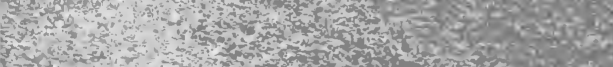

(1)

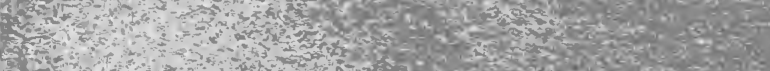

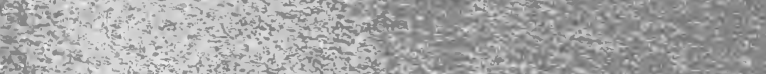

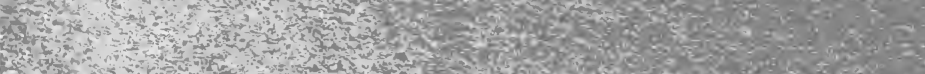

$x+1$
$H$

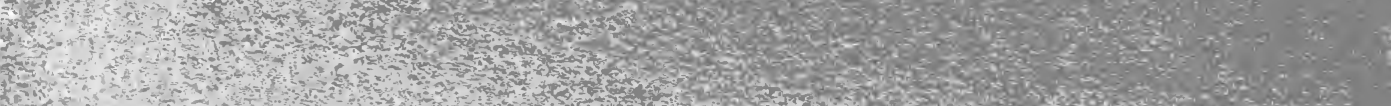
(3) 


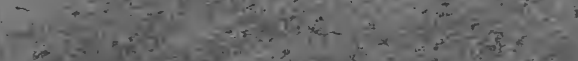

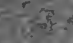

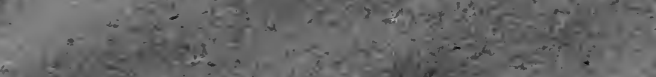 \\ $e^{2}+50$ \\ U.}

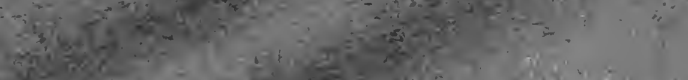

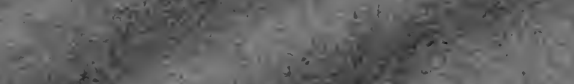

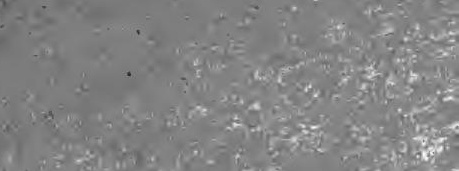

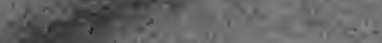

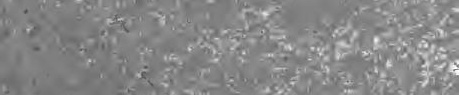

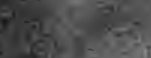

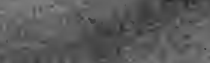

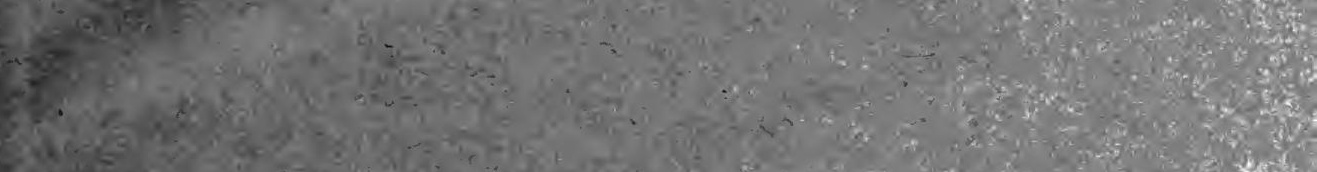

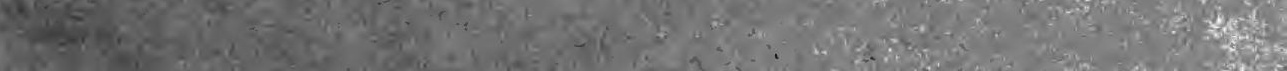

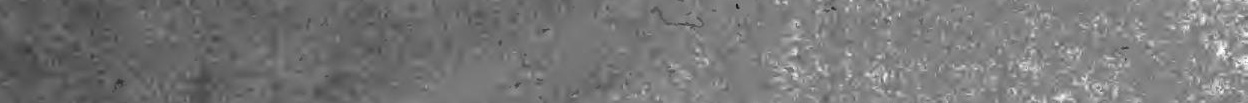

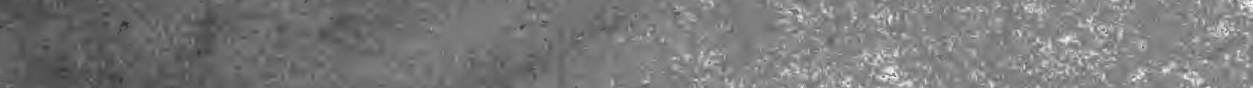

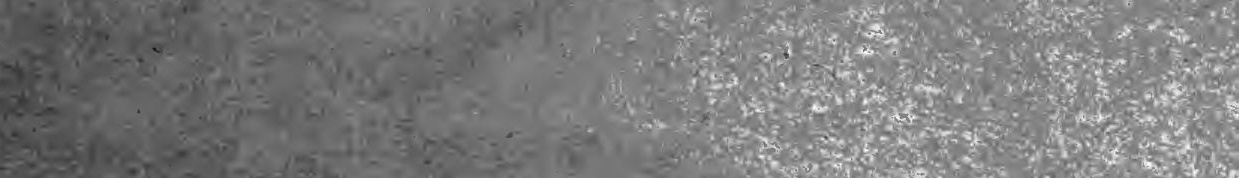
(1)

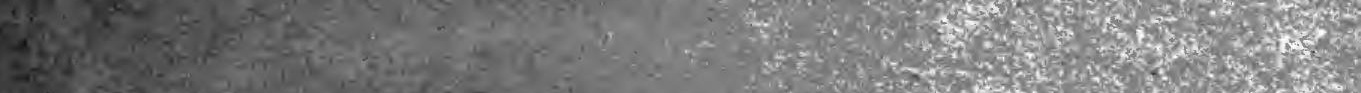

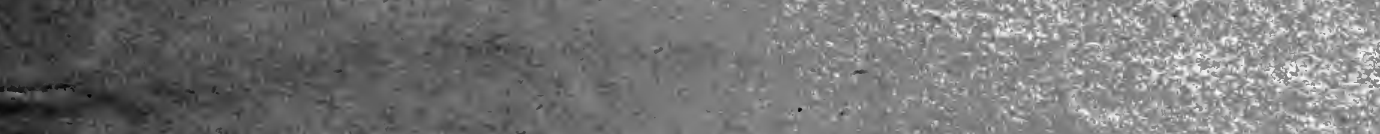
f

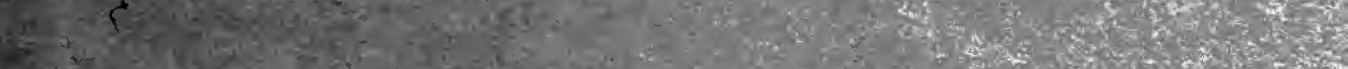

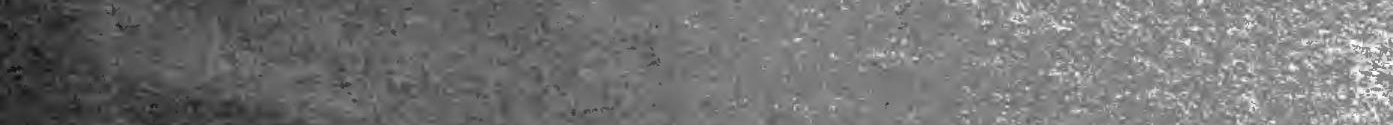

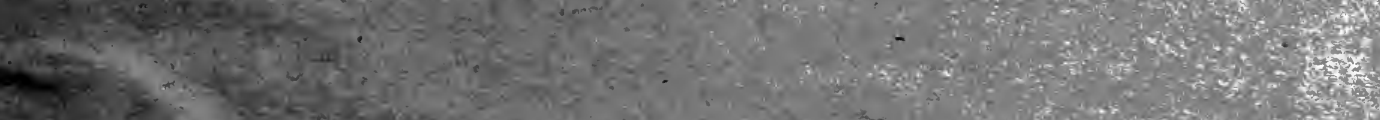

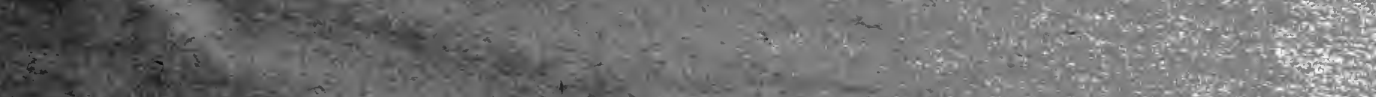

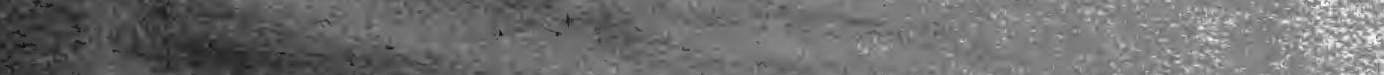

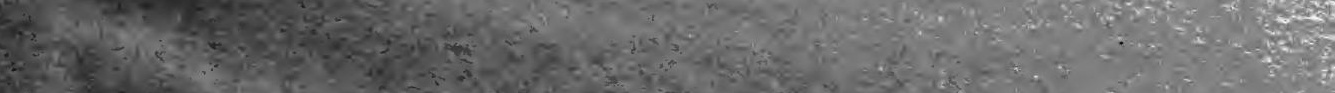
(5)

(2)

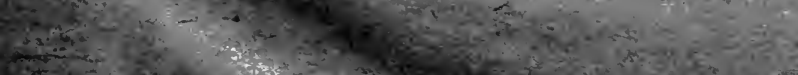

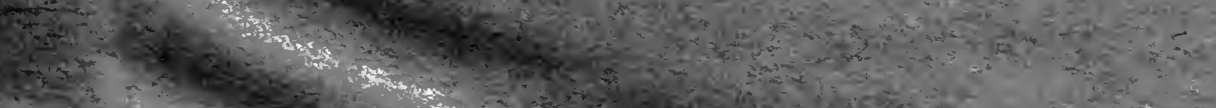




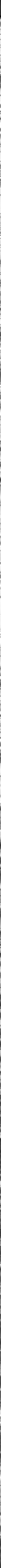




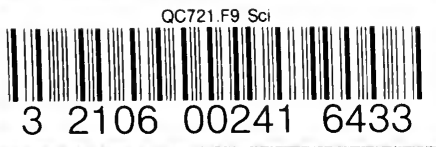

THE UNIVERSITY LIBRARY

UNIVERSITY OF CALIFORNIA, SANTA CRUZ SCIENCE LIBRARY

This book is due on the last DATE stamped below. 
